\section{Detection of Actomyosin-type Protein at the Surface of Dissociated Embryonic Chick Cells}

We have previously shown ${ }^{1}$ that antibodies prepared against smooth muscle actomyosin and capable of reacting with fibroblasts of connective tissue and with thrombocytes (platelets) markedly reduced the aggregative competence of embryonic chick muscle and liver cells. These antibodies were type specific and did not react with skeletal or cardiac striated muscle actomyosin nor with the $\left(\mathrm{Na}^{+}, \mathrm{K}^{+}, \mathrm{Mg}^{2+}\right)$-ATPase from human erythrocyte ghosts ${ }^{2}$. The same antibodies blocked the activity of the $\mathrm{Ca}^{2+}$-dependent myosin ATPase of smooth muscle actomyosin ${ }^{3}$. Antibodies directed against striated muscle actomyosin and capable of blocking the activity of the $\mathrm{Ca}^{2+}$-dependent ATPase of this protein did not produce the aggregation-inhibitory effect. This led to the suggestion that the effect was the result of the antibodies against smooth muscle actomyosin reacting with an actomyosin of similar type at the surface of the muscle and liver cells ${ }^{1}$.

These findings are in keeping with the theory that a surface-localized actomyosin-like protein with rudimentary contractile properties is involved in cell adhesion ${ }^{4}$ and might be concerned with the movement of linkage sites ${ }^{5-7}$, on which adhesion may depend. But the results hitherto did not provide evidence indicating attachment of the "inhibitory" antibodies to analogous antigens at the cell surface: such evidence would validate the suggestion that the aggregation-inhibitory effect was accompanied by the reaction of the "inhibitory" antibodies with surfacelocalized antigens. We now report the results of experiments, using the fluorescent antibody technique, which reveal the presence of actomyosin-like protein with an antigenic similarity to smooth muscle actomyosin at the surfaces of muscle and liver cells from chick embryos.

The required tissue from 9 day old chick embryos was dissociated into separate cells with 0.25 per cent trypsin in Hanks balanced salts solution ${ }^{8}$. The cells were suspended in Eagle's minimal essential medium containing 10 per cent calf serum, and cultured in Leighton tubes at $37^{\circ} \mathrm{C}$ for $24 \mathrm{~h}$. The $\gamma$-globulin fractions prepared from antisera against smooth muscle actomyosin of chicken gizzard (GAM) and chicken pectoralis muscle actomyosin (PAM), respectively, were conjugated with fluorescein isothiocyanate ${ }^{9,10}$. The cells attached to the coverslip were washed with Dulbeceo physiological saline before being treated with the conjugate ${ }^{11}$. The preparations were washod thoroughly and mounted in 70 per cent glyecrol-glyeine buffer $(p \mathrm{H} 8 \cdot 6)^{10}$.

The surface of the cells from both the embryonic muscle and liver tissue reactedaccording to the distinctive green fluorescent staining -only with the anti-GAM $\gamma$-globulins. These, we have shown (unpublished results of R. B. K., B. M. J. and U. G.-S.), inhibit cell aggrogation as effectively as antiserum against actomyosin from uterus smooth muscle (anti-UAM) ${ }^{1}$. The antiGAM $\gamma$-globulins were irreversibly attached to surface antigenic sites. The conjugated $\gamma$-globulin fractions from both the preimmunization rabbit serum (control) and the anti-PAM serum did not stain the cell surface.

Thus fluorescent anti-GAM $\gamma$-globulins can react with surface-localized actomyosinlike protein having antigenic properties similar to that of smooth muscle actornyosin. Such a reaction between GAM $\gamma$-globulins and the surface of the embryonic chick cells, leading to a reduction in the aggregative competence of these cells, strengthens the view ${ }^{1}$ that cell adhesion involves the participation of surface-localized actomyosin-like protein.

We thank Mrs Barbara Jones and Miss Barbara Morris for skilled technical assistance, the Science Research Council for grants and the Deutsche Forschungsgemeinschaft for aid in this investigation. U. G-S. received a grant from EMBO for work in the Cellular Biology Unit of this department.

UTE GRöscheL-STEWART

BRYN M. JoNES

Richard B. Kemp

Department of Zoology,

University College, Aberystwyth.

Received April 21, 1970.

${ }^{1}$ Jones, B. M., Kemp, R. B., and Groschel-Stewart, U., Nature, 226, 261 (1970).

${ }^{2}$ Gröschel-Stewart, U., Experientia, 25, 601 (1969).

${ }^{3}$ Gröschel-Stewart, U., Abst. Fifth Symp. Fed. Europ. Biochem. Sitr'., 255 (1968).

' Jones, B. M., Nature, 212, 362 (1966).

${ }^{6}$ Jones, B. M., Science J., 3, 73 (1967).

6 Jones, B. M., and Morrison, G. A., J. Cell Sci., 4, 799 (1969).

'Jones, B. M., and Kemp, R. B., Exp. Cell Res. (in the press).

${ }^{\circledR}$ Kemp, R. B., Jones, B. M., Cunningham, I., and James, M. C. M., J. Cell Sci., 2, 323 (1967).

${ }^{8}$ Coons, A. H., Int. Rev. Cytol., 5, 1 (1956),

${ }^{10}$ Roitt, I. M., and Doniach, D., Autoimmune Serology (World Health Organization, Geneva, 1967).

${ }^{11}$ Gröschel-Stewart, U., and Doniach, D., Immunology, 17, 991 (196i!).

\section{Structure of the Subunits in the Thick Luminal Membrane of Rat Urinary Bladder}

A sUBSTRUCTURE of hexagonally arranged subunits has been reported in the luminal membrane of the superficial cells lining the rat urinary bladder ${ }^{1,2}$. Preliminary examination of electron micrographs of negatively stained membranes in an optical diffractometer (unpubished observations of R. M. H., R. W. Horne and G. J. Hills) suggested that each subunit was a hexamer composcd of six smaller particles. Vergara, Langley and Robertson ${ }^{3}$ described a similar hexagonal lattice in the mouse bladder luminal membrane. Their optical filtering technique revealed a lattice of hexamers skewed by $19^{\circ}$ to the axis of the lattice. This communication describes how further detail has been resolved in the substructure of the membrane by a modification of the linear integration technique of Markham, Hitchborn, Hills and Frey ${ }^{4}$.

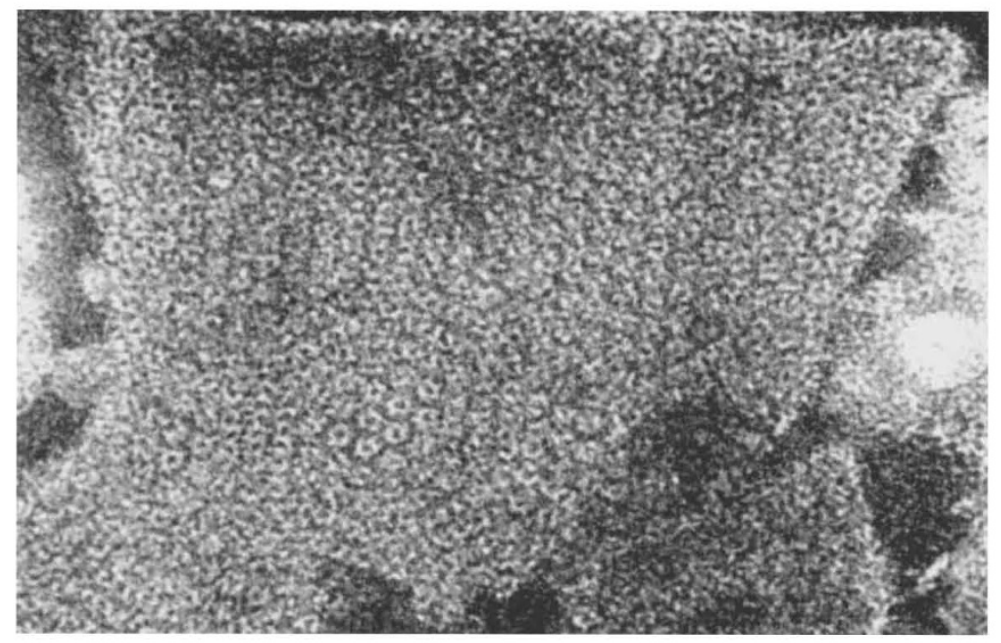

Fig. 1. A fragment of rat bladder luminal membrane, obtained by negatively staining fresh scrapings of transitional epithelium with 2 per cent potassium phosphotungstate, $p H$ ing $140 \AA-150 \AA . \quad(\times 200,000$. 